\title{
O nomadismo como função estética nos contos de Lima Barreto
}

\author{
Nomadism as an aesthetic function in Lima Barreto's short stories
}

\author{
Francisco H. Arruda de Oliveira* \\ arrudace@yahoo.com.br \\ Instituto Federal do Maranhão \\ Katia Aily Franco de Camargo ** \\ kafcamargo@gmail.com \\ Universidade Federal do Rio Grande do Norte
}

\begin{abstract}
RESUMO: O estudo crítico sobre o conjunto da obra de Lima Barreto tem se posicionado, desde Francisco de Assis Barbosa, na década de 1950, passando por estudiosos como Sevcenko (1985), Resende (2004) e, mais recentemente, Schwarcz (2017), na perspectiva de escrita engajada socialmente, em especial com questões ideológica e racial. O objetivo deste trabalho é analisar a produção barretiana sob o viés nômade, o que explicaria a aproximação e a repulsa, em sua obra, a diversos nichos sociais - como o negro, o suburbano, a academia, etc.. Esses paradoxos não conseguem ser explicados pela crítica cultural, pois inserem autor e obra numa redoma ideológica em que os aspectos estéticos do texto não são observados. Nesse sentido, este artigo define e analisa recursos estéticos nos contos de Lima Barreto como primeiro passo de investigação; em seguida, procedese à análise semântica e contextual e, por fim, à explicação do material em estudo à luz do nomadismo de Flusser (2007). É possível inferir que os elementos estéticos analisados aqui sugerem deslocamentos de valores e assunção de outros - esse gesto nômade cumpre uma função: a arte como elemento de comunhão entre os homens, pois ao se desprender de valores considerados eternos, como, por exemplo, identidade e classe social, eliminam-se também os preconceitos. Nesse sentido, sua escrita é fluida, não se fixando - cultural ou socialmente - em um ponto específico, transita entre estes, como um nômade que precisa cortar os laços com o sectarismo ideológico e manter a distância dos agrupamentos sociais para melhor observar seus paradoxos, pois o que está em jogo não é uma bandeira social, e sim uma defesa estética.
\end{abstract}

PALAVRAS-CHAVE: Conto. Estética. Lima Barreto. Nomadismo.

\footnotetext{
* Doutorando em Estudos da Linguagem, área Literatura Comparada, pela Universidade Federal do Rio Grande do Norte (UFRN). Atualmente é professor do Instituto Federal do Maranhão (IFMA). O presente trabalho foi realizado com o apoio da Coordenação de Aperfeiçoamento de Pessoal de Nível Superior - Brasil (CAPES) - Código de Financiamento 001.

" Doutorado em Letras (Língua e Literatura Francesa) pela Universidade de São Paulo (2005). Pósdoutorado em Ciência da Literatura pela UFRJ, pela Université de Saint-Quentin de Yvelines (2012) e pela Université de Sherbrooke (2019). Atualmente é professora associada da Universidade Federal do Rio Grande do Norte e colaboradora do Programa de Pós-graduação em Literatura e Cultura UFBA.
} 
ABSTRACT: From Francisco de Assis Barbosa, in the 1950s, to scholars, such as Sevcenko (1985), Resende (2004) and more recently Schwarcz (2017), critical studies on Lima Barreto's oeuvre have categorized it as a socially engaged writing, especially in relation to ideological and racial issues. This paper aims to analyze Barreto's literary output under the approach of nomadism, which explains the existence of approximation and rejection in his work to different social groups, such as the black, the suburban, the academy, etc. This paradox cannot be explained by cultural criticism because the author and his work would be placed in an ideological web in which the aesthetic aspects of the text are not observed. In this sense, this article defines and analyzes the aesthetic resources used in Lima Barreto's short stories as the first element of the investigation; then, the semantic and contextual analysis is carried out, and, finally, the material under analysis is explained in the light of Flusser's idea of nomadism (2007). It is possible to infer that the aesthetic elements analyzed herein suggest displacements of values and the assumption of others - this nomadic approach fulfills a function: art is an element of communion among men, because when it is detached from values considered eternal, such as identity and social class, prejudices are also eliminated. In light of this, his writing is fluid; it is not fixed - culturally or socially — at a specific point. It moves like a nomad who needs to cut off ties with ideological sectarianism and keep distant from social groupings in order to better observe their paradoxes: what is at issue is not a social flag, but an aesthetic defense.

KEYWORDS: Short stories. Aesthetics. Lima Barreto. Nomadism.

\section{INTRODUÇÃO}

Após o surgimento do Centre for Contemporary Cultural Studies, na Universidade de Birmingham, em 1964, a crítica literária e seus métodos voltaram-se - numa constante crescente - para a produção proveniente da cultura de massa, numa clara aversão aos estudos do clássico ${ }^{1}$. Temas como racismo, feminismo, pós-colonialismo, entre outros, passaram a compor a teoria que busca estudar e compreender as representações culturais na literatura: os Estudos Culturais. (MATTELART; NEVEU, 2004, p. 55).

Dentro do discurso literário, a cultura torna-se ferramenta capaz de evidenciar as relações de poder e de formação de identidades. Nesse sentido, questões de gênero, cor, sexo, geográficas, classe etc., são tomadas como parâmetros para atestar o nível de engajamento do escritor, assim como situar a sua obra na esteira de movimentos sociais.

A euforia, entretanto, causada pelos estudos culturais, provoca visões míopes acerca do objeto literário, pois as análises, sobre os diversos temas, são realizadas

\footnotetext{
${ }^{1}$ A crítica literária deslocou seus estudos e métodos das obras canônicas, ditas clássicas e universais, para a produção da cultura de massa e populares. Essa guinada crítica e literária vai procurar conceder visibilidade ao que é periférico como forma, também, de se opor à tradição.
} 
a partir de posições políticas, ideológicas e sociais. Dessa forma, o elemento estético fica em segundo plano, pois a crítica cultural faz o movimento inverso, isto é, vai daquilo que é externo à obra para o interno, em que o primeiro surge como premissa do segundo.

Antonio Candido (2006) afirma que a realidade referencial não pode ser o fim da obra, mas, sim, parte da sua estrutura. A lição posta pelo crítico brasileiro nos serve para compreender que o que é externo à obra não é, necessariamente, descartado, mas não pode ser tomado como princípio para sua análise. De outra forma, estaríamos particularizando a escrita literária e reduzindo-a a aspectos culturais ou sociais - esquecendo por completo da estética. Os elementos externos à obra, o que inclui o quadro de referências sociais e culturais da sua produção, passam a compor a estrutura discursiva como parte integrante, excluindo, assim, qualquer possibilidade de ser entendida como afixo ou chave de compreensão literária.

Nesta linha dos estudos culturais, escritores do passado ou do presente passam a ser analisados como representação dos anseios da contemporaneidade. É o caso de Lima Barreto, o qual surge no seio da crítica literária cultural na acepção de escritor negro, marginalizado, pobre e defensor de nichos sociais, em especial, da luta contra o racismo, tornando-se, assim, um símbolo da voz afrodescendente no Brasil em primórdios do século XX.

A hipótese deste artigo, portanto, é a de que Lima Barreto não é essa voz que se impõe em favor de grupos sociais, mas, sim, que transita por todos os campos possíveis em defesa da estética. Com isso, pretende-se analisar parte de sua obra a partir da estética e do conceito de nomadismo emergente de Flusser (2007), em que buscar-se-á evidenciar o trabalho estético na escrita de Lima Barreto na qual o nomadismo aparece como uma possibilidade para o entendimento e discussão da linguagem paradoxal. Usar-se-ão, para tanto, dois contos que versam sobre a temática do feminismo a partir de posições discursivas, aparentemente, contraditórias. Mas, antes, é necessária uma breve localização do estado da arte da obra de Lima Barreto na contemporaneidade.

\section{Lima Barreto hoje!}


Tornou-se indispensável tomar a escrita de Lima Barreto como manifestação social sobre diversos assuntos da contemporaneidade, tais como: a questão do negro, da mulher e dos marginalizados. Essa posição tem seu ápice na nova biografia sobre o autor de Policarpo Quaresma lançada em 2017, por Lilia Moritz Schwarcz ${ }^{2}$. Entretanto, as bases foram lançadas bem antes.

Quando Francisco de Assis de Barbosa organizou as obras de Lima Barreto e escreveu a sua biografia, o crítico literário abriu as possibilidades para que a recepção da produção barretiana fosse vista sob o olhar do discurso ideológico "sobre raça, assimilação e papel do negro na cultura brasileira" (FIGUEIREDO, 2017). Isso acontece porque Barbosa (2002) visava resgatar Barreto do ostracismo literário ao qual fora lançado pelo foco dado ao modernismo. Nesse sentido, Barbosa não desenha, propriamente, uma figura heroica do autor de Isaías Caminha, mas abre caminhos para compreensões ideológicas da escrita barretiana. Será por esse viés que críticos e estudiosos posteriores, aliados às teorias contemporâneas e à necessidade de reinventar o escritor maldito, ratificarão a ideia de Lima Barreto como escritor que versa sobre a defesa de grupos sociais.

Em um estudo considerado, hoje, como clássico sobre a literatura na belle époque, Nicolau Sevcenko (1985) buscou construir a estética de Lima Barreto sob dois vieses: i) o intelectual cidadão - escritor que, muito mais que observar, vivencia as derrotas do seu tempo e registra suas impressões na escrita e; ii) a literatura como missão humanitária - da experiência dos preconceitos e de toda forma de opressão e humilhação, nasce a escrita comprometida com a solidariedade humana. Dos dois pontos do trabalho de Sevcenko, apenas o primeiro é amplamente utilizado, pela maioria dos estudiosos, para caracterizar a produção de Lima.

Sem perceber, Sevcenko (1985) insere o intelectual cidadão na faceta da literatura como missão. $\mathrm{Na}$ verdade, o segundo ponto não é um desdobramento do primeiro, mas parte de um único elemento: o engajamento com o homem por meio da arte. Entretanto, os trabalhos posteriores ao de Sevcenko concentraram-se em personificar o social na escrita barretiana e encontraram - na contemporaneidade a germinação para o crescimento dessa vertente social no seio dos estudos culturais.

\footnotetext{
${ }^{2}$ Referência ao livro Lima Barreto: triste visionário, lançado na Feira Literária de Paraty (FLIP), em 2017, em que Lima foi o homenageado.
} 
Note-se que não há problema em pesquisar sobre a obra do autor de Policarpo Quaresma por meios dos Cultural Studies, a questão é se o caminho teórico escolhido é o mais viável - considerando os momentos de recepção, produção e circulação - e se o pesquisador "escuta" o texto literário ou o subordina à teoria, isto é, a teoria passa a ditar o funcionamento interno da obra, bem como a define, numa clara aversão ao ensinamento de Candido (2006) supracitado.

Os questionamentos suscitados nascem da necessidade de se considerar os paradoxos existentes nas formulações ideológicas de Lima Barreto e do perigo de inserir sua obra numa redoma de discursos bem definidos e acabados, o que, de certa maneira, restringiria $o$ trabalho estético com a linguagem $e$, consequentemente, o seu valor literário.

Não constitui objetivo deste artigo negar algum tipo de engajamento social ou ideológico de Lima, mas contestar o lugar já sacralizado que a crítica - a partir dos estudos culturais - alçou à sua obra, que é a de porta voz ou defensora de determinados nichos sociais, especialmente, o negro. A construção dessa tradição se faz por motivos diversos que são focados muito mais nas expectativas da crítica contemporânea do que propriamente nas obras em estudo.

Note-se, a título de exemplo, como é tratada, atualmente, a questão do negro na literatura de Lima. Para Schwarcz, unir o quadro de referências históricas, sociais e culturais do autor com a do pesquisador é algo viável:

Historiadores são assim: voltam ao passado com indagações novas; aquelas de sua época. [...] Foi dado à minha geração presenciar a eclosão da linguagem dos direitos civis no Brasil - o direito da diferença na igualdade, e vice-versa -, e é possível reler Lima Barreto com base nas suas denúncias e nas angústias que ele sentiu diante de uma série de marcas que a sociedade cria e transforma em diferença e preconceito. Aí está, pulsante, a questão racial, para lembrarmos de um tema sensível e definidor da pessoa e de toda a obra do autor (SCHWARCZ, 2017, p. 16; grifo nosso).

Os questionamentos sobre raça ${ }^{3}$, racismo e o espaço do negro são tomados na obra de Lima Barreto pelo olhar contemporâneo, ao ponto de a autora afirmar

\footnotetext{
${ }^{3}$ Nos anos iniciais do século $\mathrm{XX}$ ainda prevalecia a ideia de raça como um conjunto de características físicas comuns hereditárias, como atesta o Le Trésor de la Langue Française informatisé. Do ponto de vista teórico, são as ideias deterministas de Taine sobre raça que a definem como fator hereditário e inato, conforme consta na introdução do livro Histoire de la littérature anglaise. Segundo Oakley (2011), Lima Barreto compreende raça, conjugada com o meio social e o momento, como condicionante para criação artística, pois esse conjunto de fatores pode interferir na recepção, isto é,
} 
que a questão racial é definidora do conjunto da obra do autor carioca. A princípio, não seria um problema estudar isso dentro do círculo histórico da primeira década do século XX, mas ao suplantar o momento de produção pelos anseios que são próprios da época do pesquisador, cria-se uma tendência para apontamentos ideológicos sobre a produção barretiana, os quais chegam a ser radicais:

Afrodescendente por origem, opção e forma literária, Lima Barreto combateu todas as formas de racismo, aqui e nos Estados Unidos [...] e desenhou suas personagens com particular ternura. (SCHWARCZ, 2017, p. 10; grifo nosso).

A definição de literatura afro-brasileira ou afrodescendente não é muito clara no Brasil quando comparada com a literatura afrodescendente americana. Para estes, ser negro já é suficiente para definir a escrita como da negritude, independente de engajamento ou não, com as questões identitárias. Soma-se a isso, o fato de os afroamericanos serem mais conscientes e engajados politicamente que os afro-brasileiros, como atesta Andrews (1985), o que em determinada medida se explica devido a discriminação racial entre os americanos ter funcionando como lei, o que no Brasil não ocorrera.

O professor e pesquisador Eduardo de Assis Duarte, no livro Poéticas da diversidade (2002), não deixa explícito um conceito de literatura afro-brasileira mas, por meio dos exemplos que utiliza, podemos inferir que, para o autor, a literatura negra é aquela compromissada, política e ideologicamente, com a negritude. Nesse ponto, pode-se fazer um elo com a literatura afroamericana, pois ela também é temática como nos trópicos.

Nesse sentido, no Brasil, literatura afrodescendente é sinônimo de escrever sobre o negro, porém, esta é uma definição contemporânea, não pertencente ao tempo de Lima Barreto, pois o termo e o conceito nem ao menos existiam no início do século $X X^{4}$. Também não é possível afirmar que o escritor carioca combatesse o racismo no Brasil e nos Estados Unidos. Isso seria supor que sua voz fosse atuante e conhecida entre os americanos, quando na verdade Lima Barreto ainda lutava pelo

não se trata de uma ideia hereditária e determinista como em Taine, mas de considerar a raça como elemento modulador da arte.

${ }^{4}$ Foram realizadas consultas online em dois dicionários de Cândido de Figueiredo (1899; 1913) pelos vocábulos afrodescendente e afro-brasileiro, mas os resultados deram como inexistentes. Com isso, atribuir o conceito de escritor afrodescendente ou afro-brasileiro a Lima Barreto se mostra inviável, tanto pela ausência de tais termos em seu tempo, como pelos vocábulos assumirem valores ideológicos relativos a questão racial no século XXI. 
reconhecimento em seu país. Portanto, o que Schwarcz (2017) faz é inserir um conceito do agora no seio da produção barretiana, desconsiderando, assim, o quadro de referências históricas e culturais do autor e da produção de sua obra.

O caso do negro é apenas um exemplo, mas há outros temas que são utilizados para definir a obra de Lima Barreto como engajada, sem as devidas reflexões do texto e da história - e comprometidas apenas com a teoria e as necessidades do contemporâneo - caso esse é, por exemplo, o do feminismo que será analisado aqui.

Portanto, é justamente dessa passagem da tradição literária e crítica sobre a obra de Lima Barreto - que a define ligada ao tema e pouca atenção é dada aos paradoxos - que se pretende tratar neste artigo. A obra do autor de Policarpo Quaresma será abordada considerando as contradições presentes no material estético que dialogam com a perspectiva do nomadismo emergente de Flusser (2007). No subitem que segue, passar-se-á a uma discussão teórica, mesmo que parcial, desse conceito.

\section{Noção de nomadismo}

Considerando-se a tese do intelectual cidadão de Sevcenko (1985), duas perspectivas se abrem para os estudos barretianos: i) o de voz dos marginalizados, como aponta Beatriz Resende (2004), e ii) o do escritor afrodescendente, conforme atesta Schwarcz (2017). No primeiro caso, a literatura é vista como o espaço para aqueles que não têm voz e necessitam ser representados. Abordando o discurso literário de Lima Barreto nessa perspectiva, inevitavelmente, abre-se lugar para a crítica que defende a segunda - a da questão racial. Afinal, para a crítica, ao dar voz a grupos menores na sua literatura, o escritor carioca sofrera ostracismo em seu tempo e surge agora - como numa espécie de reparação histórico-literária, ou como Kafka e seus precursores, de Borges - definido por elementos culturais legítimos, mas que não estabelecem diálogo com a estética e com os paradoxos da sua escrita.

Se analisado por essas perspectivas, o estudo fica restrito e perde-se a oportunidade de uma discussão mais complexa sobre a obra e figura de um escritor que, ao mesmo tempo em que chamava à cena o povo do subúrbio na sua escrita, guardava repulsas pelas atitudes daquela gente. Por este motivo, vemos a 
necessidade de estudar Lima Barreto como uma voz sob tensão, dialógica por excelência, entre essas categorias.

Num primeiro momento, é preciso entender o que seria o nomadismo e como ligá-lo à obra de Lima Barreto. O filósofo judeu Vilém Flusser, nascido em Praga, desenvolve a ideia de nomadismo, de forma muito peculiar, na condição de migrante fugindo da invasão nazista à sua cidade natal. Para Flusser, a pátria não é um valor eterno, mas uma função específica na sociedade que se perdeu quando o homem rompeu com o sedentarismo, isto é, estar no mundo não é estático, mas um constante fluxo:

Nós, os inúmeros milhares de migrantes (sejamos trabalhadores estrangeiros, expatriados, fugitivos ou intelectuais em visitas frequentes a seminários) nos reconhecemos então não como marginais, mas sim como vanguarda do futuro. Os vietnamitas na Califórnia, os turcos na Alemanha, os palestinos nos países do Golfo Pérsico e os cientistas russos em Harvard surgem não como vítimas dignas de compaixão que devem receber ajuda para retornar à pátria perdida, mas sim como modelos a serem seguidos por sua suficiente ousadia (FLUSSER, 2007, p. 223).

Ultrapassar as fronteiras constitui-se uma ousadia e modelo a ser seguido porque significa derrubar barreiras impostas pela cultura, história, tradição, etc., portanto, fronteira passa a ter um sentido metafórico significando rompimento com aquelas barreiras ou nós, expressão esta usada por Flusser (2007).

Desse entendimento - muito mais que a pátria - nenhum valor é eterno para Flusser, tudo se constitui uma função passível de mutações com a evolução do homem e a passagem do tempo. Daí, a função específica, ou técnica, que o homem tem na sociedade define a ideia de pátria, muito mais que um espaço geográfico ou uma porção territorial.

Dessa forma, o homem pode habitar e ser apátrida ao mesmo tempo, pois habitar é uma necessidade humana (seja em que condições for), mas ser apátrida é uma condição provocada pelo fim do sedentarismo, isto é, pelo rompimento de um nó ou, em outras palavras, pelo nomadismo emergente (FLUSSER, 2007).

A partir de Flusser, pode-se perceber que nada no homem é ancoragem ${ }^{5}$, nem mesmo suas marcas culturais, mas que não é possível realizar um rompimento por completo entre o homem e os elementos da pátria, da cultura, da religião etc. $O$ gesto nômade - o rompimento com as amarras sociais - é tratado como ato heroico,

\footnotetext{
${ }^{5}$ Cf. Hall (2006).
} 
mas, ainda assim, é visto como uma função que serve, por meio dos laços que não se desfazem por inteiro, para desfazer os preconceitos:

No meu caso, depois do rompimento de um nó górdio após o outro, do nó de Praga, do nó de Londres, do nó paulistano, reconheci não apenas a equivalência (assim como a torpeza) de todos os preconceitos ali domiciliados (e, antecipadamente, reconheci os preconceitos domiciliados em Robion), mas sobretudo o fato de que, a cada rompimento de nó górdio, crescia a minha liberdade de julgar, de decidir, de agir (FLUSSER, 2007, p. 224-225).

Note-se que, para o sujeito nômade, o rompimento com aquilo que lhe é habitual é necessário para confrontar os preconceitos, alcançar a liberdade e agir. $\mathrm{O}$ seu agir - só possível pela liberdade - é consciente, por isso o homem nômade não pergunta mais livre de quê, mas sim livre para quê (FLUSSER, 2007). Esse questionamento sobre a liberdade tem resposta na nova função que o homem, agora nômade, exercerá no seu meio.

Dessa forma, a noção de nômade emergente não fica restrita apenas àqueles que se tornaram expatriados, mas também àqueles que habitam - os domiciliados e romperam os laços culturais e sociais, isto é, tornaram-se nômades, livres, para agir. O nomadismo não apaga os laços que unem homens e cultura - isso seria próprio da utopia -, mas proporciona liberdade para criar ligações sem serem impostas por condicionantes contumazes, como pátria, gênero, cor da pele, condição social etc.

O nomadismo emergente proporciona uma reflexão constante sobre si e o mundo, por isso o sujeito nômade mostra-se em posições, aparentemente, paradoxais já que ele vive na dialética entre o habitual e o inabitual. Para Flusser (2007), essa tensão é a própria consciência que oscila entre polos, aparentemente, antagônicos: público e privado, centro e periferia etc., realizando uma função.

Nesse sentido, Lima Barreto é essa figura em trânsito, pois a sua voz aparece como desafiadora da literatura e do sistema político-social dominante em sua época e, ao mesmo tempo, como aquela que vai estreitar os laços com o sistema numa tentativa de ser membro de um seleto grupo da sociedade: o conjunto de intelectuais e literários referenciados social e culturalmente naquele momento histórico.

O gesto nômade na escrita de Lima Barreto surge com uma função peculiar: de a arte proporcionar a comunhão entre os homens, logo não é possível ligá-lo a um grupo específico. É preciso olhar para o conjunto da sua obra para discutir a 
complexidade na sua estética, e não a tomar de forma descontextualizada e pontual, pois, ao se comparar um conjunto de textos sob o mesmo tema, percebe-se que o engajamento em prol de nichos sociais mostra-se paradoxal. A questão é entender que não é uma postura contraditória, mas o exercício de uma função estética.

Tal função corrobora para o "deslocamento de valores, conceitos e princípios" (FIGUEIREDO, 2017, p. 47) no discurso, e isso se manifesta por elementos estéticos como: i) o uso do discurso indireto livre, o qual atribui valor ao personagem; ii) o uso de tempo e modo verbais que indicam movimento, como o gerúndio; e iii) a inserção do discurso direto, como forma de esvaziar e ironizar os valores apontados no discurso indireto livre.

O estudo semântico das categorias estéticas apontadas acima, juntamente com a contextualização histórica da belle époque carioca, proporciona um caminho para compreender a escrita de Lima Barreto como nômade, acreditando que a apropriação e o esvaziamento de identidades, isto é, o rompimento com as amarras culturais e sociais, seja a forma de burlar os preconceitos por meio da acepção de uma nova função. Passemos à análise dos textos.

\section{Uma breve análise}

A primeira narrativa a ser analisada chama-se Lívia, conto originalmente publicado na obra Histórias e Sonhos, cuja primeira edição é de 1920, portanto, publicado em vida por Lima Barreto. Foi usada, neste artigo, a versão que se encontra na terceira edição do livro (1956), obra organizada por Francisco de Assis Barbosa e prefaciada por Lúcia Miguel Pereira.

Lívia é uma jovem sonhadora, com pouco mais de 20 anos, que deseja enriquecer, sair do subúrbio e conquistar sua liberdade por meio do casamento. Ela divide-se entre duas figuras - Godofredo e Siqueira - observando qual dos dois é mais viável para realizar seu sonho de mudança. Ao mesmo tempo é repelida dos seus sonhos pelas figuras familiares - o cunhado, o pai e a mãe - os quais são encarregados de trazê-la à sua realidade suburbana, porém o que a caracteriza é a fantasia:

E todos os dias quando ela, de manhã cedo, ia, ainda morrinhenta da cama, preparar o café matinal da família, ia toda envolvida num nevoeiro de sonhos, sonhando durante um demorado dormir de oito horas a fio (LIMA BARRETO, 1956a, p. 151). 
A estrutura do conto não se apropria da estética modernista ${ }^{6}$, não há rupturas com a forma clássica na inserção do discurso das personagens, por exemplo. Contudo, a linguagem se constitui um misto de sofisticação e, ao mesmo tempo, simplicidade no uso do discurso. Isso fica mais claro nos momentos em que o narrador atribui valor à Lívia por meio do discurso indireto livre:

Aquele nariz grosso, aquela testa alta, o bigode ralo, não eram dele; eram antes do Siqueira. Estudante de farmácia, filho do agente. Esse poderia Ihe dar aquilo - a Europa, o luxo - pois que formado ganharia muito. [...] E era muito melhor! O Siqueira, afinal, ia formarse, seria um marido formado, ao braço do qual, se não fosse à Europa, viria a gozar de maior consideração (LIMA BARRETO, 1956a, p. 154).

Importante frisar que o conto inicia com Lívia acordando, ainda morrinhenta da cama, portanto, as poucas intromissões do narrador, que se confundem com os pensamentos da personagem, na citação acima, servem para reforçar a figura sonolenta e sonhadora da jovem. Nesse sentido, o uso do discurso indireto livre atribui um valor que é quebrado com a inserção do discurso direto:

- Lívia! Traz o meu guarda-sol que ficou atrás da porta do quarto. Depressa!... Anda que faltam só oito minutos para o trem!

E como se demorasse um pouco, o Marques, redobrando de vigor no timbre, gritou:

- Oh! Cos diabos! Você ainda não achou! Safa! Que gente mole! (LIMA BARRETO, 1956a, p. 152; grifo nosso).

As vozes do cunhado e da mãe são as que despertam, momentaneamente, Lívia da inércia, mas de uma forma bruta e autoritária, sem conferir espaço para concretização de suas ações, por isso o uso de verbos que indicam movimento serem abundantes na narrativa. Entretanto, esse movimento pertence mais ao mundo da fantasia - do sonho - que da realidade:

Por vezes - lá na cozinha [Lívia], só vigiando pacientemente a água que fervia... [...] ela, d'olhos parados, presos a uma linha do assoalho, levando compassadamente a xícara aos lábios, ficava a

\footnotetext{
${ }^{6}$ A estética modernista, no Brasil, inova no uso experimental da linguagem, com a inserção do fluxo de consciência, que realiza quebras sintáticas, no surgimento de um novo léxico e na inclusão de temas populares e do folclore brasileiro. (LAFETÁ, 2000). Observador da modernidade e das mudanças causadas por ela, Lima Barreto insere muitos desses pontos estéticos - como os temas populares - na sua escrita, mas isso não o torna modernista, pois, para ele, o modernismo, com suas inspirações vanguardistas, não tinha nada de novo, como é possível atestar na sua crônica "O Futurismo", em que estabelece um diálogo com os jovens modernistas de São Paulo.
} 
um canto a pensar, remoendo a cima, procurando decifrar naqueles traços nebulosos [...] a figura viva daquele, com quem, em sonhos, se vira indo de braço dado ruas em fora. (LIMA BARRETO, 1956a, p. 151; grifo nosso).

No quadro de referências culturais e literárias da produção de Histórias e Sonhos - que se localiza no início da segunda década do século XX - encontra-se a modernidade que desperta no sujeito a experiência marcada pela subjetividade. As mudanças urbanas, culturais, sociais, demográficas e econômicas estão na base da experiência do eu em que este se desloca no espaço, buscando educar e ampliar seu olhar para as diversas percepções (FIGUEIREDO, 2017, p. 20). Dessa forma, percebe-se que na estética barretiana estão presentes elementos, como os verbos de movimento, que demarcam os diversos deslocamentos sempre em busca de uma visão panorâmica.

Outro exemplo de como Lima Barreto se apropria do quadro de referências de sua época diz respeito à mulher suburbana da belle époque carioca, na qual ela tem uma função específica no seio da família - a realização de trabalhos domésticos -, entretanto, se aproxima das enfants de $\operatorname{Sion}^{7}$ no que se refere à posição submissa que ocupam no espaço familiar. Por esse motivo, a personagem barretiana deposita toda sua esperança no casamento como única chance de mudança, ou seja, desvincular-se da subserviência familiar que lhe é imposta pela sua condição de: mulher, solteira, jovem e suburbana.

Lívia, em seu desejo de liberdade, não questiona, efetivamente, sobre a finalidade desta, que no conto surge sob a forma de indagações a respeito do amor, sobre o qual pensa de maneira pragmática e sonhadora. Portanto, ela foca no livre de quê - do subúrbio, do jugo do cunhado, das tarefas domésticas - e esquece o livre para quê - quais as amarras que o casamento pode trazer, qual a sua nova função, como agir.

A estrutura do conto vai favorecendo a construção de uma imagem feminina fantasiosa, romântica, submissa e ignorante, isto é, a narrativa corrobora com a função doméstica e infantilizada da mulher. Dessa forma, como afirmar que a escrita de Lima Barreto é engajada com o feminismo ou, ainda, com a emancipação feminina? Compartilhando assim com o que prega os Cultural Studies? Há, ainda,

\footnotetext{
${ }^{7}$ Segundo Jeffrey D. Needell (1993), começou a funcionar no Brasil, no ano de 1888, o Collège de Sion - escola exclusiva para meninas da elite brasileira, que eram educadas conforme a nobreza feminina francesa. As jovens eram conhecidas pelo francês perfeito, gosto pela literatura e a submissão às autoridades escolar e familiar (1993, p. 83).
} 
uma ironia sutil ao feminismo, a começar pelo nome da personagem que faz alusão a lívido, pálido, sem cor e sem ação.

Por tratar-se de uma personagem romântica - o que é necessário compreender como uma ironia barretiana - o gesto nômade, no conto, reside no fato de Lívia encontrar-se entre dois mundos sociais, em que ela acredita ser o casamento o elemento de mudança. Entretanto, todo o processo dialético entre os polos paradoxais é fruto da fantasia e da consciência de Lívia.

- Ó Lívia! Você hoje não pretende varrer a casa, rapariga! Que fazes há tanto tempo na janela?!

Obedecendo ao chamado de sua mãe, Lívia foi mais uma vez retomar a dura tarefa, da qual, ao seu julgar, só um casamento havia de livrá-la para sempre, eternamente... (LIMA BARRETO, 1956a, p. 155; grifo nosso).

A fantasia, o romantismo - o olhar da janela - é o que impede a ação de Lívia e a concretização da sua liberdade, pois o rompimento com os laços culturais e sociais que a cercam é apenas fruto da sua imaginação. Portanto, é um texto que opera com o nomadismo no uso dos aspectos estéticos - verbos de movimento e discursos direto e indireto livre - e semânticos, pois sugerem deslocamentos de valores. Entretanto, o discurso não se concretiza como liberdade para criar ligações livres de condicionantes, isto porque a ironia romântica - sugestiva numa personagem que se encontra entre o sonho e a realidade - surge como elemento indicador da inclinação para a ignorância e o excesso de fantasia do sujeito suburbano, e é isto que impede as personagens de agirem, mas não de transitarem - mesmo que seja no espaço da fantasia.

Numa análise superficial, apenas pautada na cultura, poderia se afirmar que o autor de Policarpo Quaresma guardasse aversões pela mulher suburbana ao construir uma imagem infantil e submissa dela. Mas não é o caso, pois Lima Barreto não apresenta no seu projeto literário engajamento temático, mas sim estético que busca ampliar os horizontes de percepções como uma forma da literatura intervir nas relações humanas. No intuito de evidenciar que sua literatura é feita por deslocamentos, e não engajada em temas ou ideologias, note-se, em um outro conto, como a imagem de outra figura feminina, Ermelinda, é o oposto da de Lívia.

No conto Quase ela deu o "sim"; mas..., publicado em 1921 na revista Careta - porém, neste artigo é usada a versão de 2010, organizada por Lilia Moritz 
Schwarcz - há um relacionamento entre Cazu, um malandro jogador de futebol, e Ermelinda, uma jovem viúva com dois filhos. Ermelinda tem casa própria, recebe uma pensão e a complementa fazendo costuras. Ela transita entre duas funções: a da mulher independente - será esta percepção, a possibilidade de viver às expensas da viúva, que despertará o interesse de Cazu - e o da mulher dependente, que necessita da figura masculina para sua afirmação perante a sociedade.

Marcado por um discurso linear e da tradição, o conto estrutura-se em torno de um narrador que tudo vê, contudo procura ser sutil ao caracterizar personagens, mantendo-se numa descrição física, superficial e sugestiva. Se, em "Lívia", havia a presença do discurso indireto livre que apontava para o impasse entre o sonho e a realidade favorecendo uma construção não linear, aqui ganha o reforço da voz do narrador - como forma de direcionar o olhar do leitor:

João Cazu era um moço suburbano, forte e saudável, mas pouco ativo e amigo do trabalho (LIMA BARRETO, 2010, p. 502).

De fato, da Ermelinda era viúva de um contínuo ou coisa parecida de uma repartição pública. Viúva e com pouco mais de trinta anos, nada se falava da sua reputação. Tinha uma filha e um filho que educava com grande desvelo e muito sacrifício (LIMA BARRETO, 2010, p. 502-503).

O narrador é o responsável por atribuir valores e funções aos personagens, e no seu discurso usa verbos que indicam movimento para construir imagens que apenas transcorrem indicando certeza de aonde os atos das personagens irão leválas. Entretanto, essa conviç̧ão faz parte do jogo narrativo que quer influenciar a leitura do leitor:

A viúva tomando café, acompanhado com pão e manteiga, pôs-se a olhar o companheiro com certo interesse. Ele notou e fez-se amável e galante, demorando em esvaziar a xícara. A viuvinha sorria interiormente de contentamento. (LIMA BARRETO, 2010, p. 504; grifo nosso).

A interferência na percepção do leitor concretiza-se pelo uso do discurso indireto livre, o qual favorece a voz da personagem, ou seus pensamentos, mas sempre com a participação do narrador. Dessa forma, não é possível afirmar - por mais que esteja o discurso entre aspas - a veracidade do pensamento, pois ele parte do narrador, que tudo sabe e que desde o princípio buscou orientar a leitura: 
Cazu pensou com os seus botões: "está aí um bom partido: casa própria, montepio, renda das costuras; e além de tudo, há de lavarme e consertar a roupa. Se calhar, fico livre das censuras da tia..." (LIMA BARRETO, 2010, p. 504).

Em outro momento o discurso indireto livre - o qual serve para atribuir um valor, uma função pejorativa a Cazu - aparece novamente entre aspas na organização dada por Schwarcz, entretanto, na publicação original na revista Careta, de 1921, não há aspas. Tal fato é muito mais significativo, pois ao colocar no plano textual o pensamento de Cazu, narrador e personagens se misturam para atribuir valores:

Um belo dia, após ano e pouco de tal namoro, houve um casamento na casa dos tios do diligente jogador de football. Ele, à vista da cerimônia e da festa, pensou: "Por que também eu não me caso? Por que eu não peço Ermelinda em casamento? Ela aceita, por certo; e eu..." (LIMA BARRETO, 2010, p. 505).

Um belo dia, após ano e pouco de tal namoro, houve um casamento na casa dos tios do diligente jogador de football. Ele, à vista da cerimônia e da festa, pensou: Por que também eu não me caso? Por que eu não peço Ermelinda em casamento? Ela aceita, por certo; e eu... (LIMA BARRETO, 1921).

Após atribuições e deslocamentos, as quebras de princípios são feitas pelo discurso direto, sem a intromissão do narrador. A construção da imagem de Ermelinda muda de forma radicalmente. O gesto nômade de Ermelinda encontra-se nas alternâncias de funções, pois ela rompe com as formas, pré-estabelecidas na sociedade, que conferem valores ortodoxos à mulher - como dependente do homem, casada e submissa a uma sociedade masculina que minimiza a sua ação. Após ficar viúva, ela torna-se independente dos pontos de vista financeiro e social. Contudo, a figura do malandro Cazu suscita uma possível volta à posição de mulher dependente:

- Cazu - disse ela, tendo o papel na mão - você vai à venda e à quitanda e compra o que está aqui nesta "nota". É para o almoço.

$[\ldots]$

- Anda Cazu, fez a viúva. Assim, demorando, o almoço fica tarde...

- É que...

- Que há?

- Não tenho dinheiro.

- Mas você não quer casar comigo? É mostrar atividade meu filho! Dê os seus passos... Vá! Um chefe de família não se atrapalha... É agir (LIMA BARRETO, 2010, p. 506). 
Segundo Flusser (2007), o sujeito nômade, ao romper com as funções sociais impostas, guarda uma série de ligações com o seu estado anterior. É o caso de Ermelinda, pois ela busca, no relacionamento com Cazu, desempenhar a função de mulher casada e responsável por cuidar das atividades expressamente domésticas. Portanto, não há paixão ou amor, apenas interesses de acordo com os estereótipos dos gêneros.

Esses interesses não são impactantes para a construção de uma personagem feminina menos autônoma que em "Lívia". Mesmo cultivando o desejo de passar a função de arrimo de família para Cazu, a ação de Ermelinda já sugere a liberdade para criar suas próprias ligações sem a imposição de condicionantes, afinal, Cazu era um malandro, jogador de futebol e que vivia de favor na casa dos tios, e Ermelinda o escolhe conscientemente.

Se, em Lívia, há uma crítica irônica ao casamento e à mulher, em Quase ela deu o "sim"; mas... há a presença da mulher autônoma e livre. A ironia recai sobre a figura masculina por meio de adjetivações negativas. Nesse sentido, de que ordem é esse engajamento que ora condena, ora apoia? As posições paradoxais da escrita de Lima Barreto buscam uma socialização dos homens por meio da arte ao expor suas diferenças.

\section{Conclusão}

A função primordial do nomadismo é eliminar os preconceitos, assim como é o objetivo da comunhão entre os homens presentes na estética de Lima. Portanto, um olhar sob diversos prismas é necessário - o que impede o engajamento com grupos sociais específicos. E se não é possível colocar-se dentro de um grupo, Lima Barreto passa a escrever de zonas fronteiriças ${ }^{8}$ como uma forma de afirmar-se e fugir de enquadramentos literários.

Neste artigo, apenas salientou-se posicionamentos distintos sob a mesma temática em dois contos no intuito de apontar como o nomadismo opera no conjunto da obra de Lima. Nesse sentido, compreende-se que o nomadismo pode ser uma ferramenta de leitura dos contos barretianos, por trazer perspectivas distintas

\footnotetext{
${ }^{8}$ Pratt (1999) usa o termo "zona de contato" como sinônimo de fronteira - espaço histórico e geográfico que absorve culturas. Em termos práticos, fronteira é o lugar das trocas e transferências culturais.
} 
daquelas que emanaram com os estudos culturais - a de pensar o escritor engajado em questões ideológicas e raciais - e apontar para uma literatura complexa, militante pela arte e transitando entre categorias e valores.

\section{REFERÊNCIAS}

ANDREWS, G. R. O negro no Brasil e nos Estados Unidos. Lua Nova. v. 2, n. 1, p. 52-56,1985. Disponível em: http://dx.doi.org/10.1590/S0102-64451985000200013. Acesso em: 22 set. 2018.

BARBOSA, F. de A. A vida de Lima Barreto. 8. ed. Rio de Janeiro: José Olympio, 2002.

CANDIDO, A. Formação da literatura brasileira (momentos decisivos). Rio de Janeiro: Ouro sobre Azul, 2006.

FIGUEIREDO, C. de. Novo dicionário da língua portuguesa. Lisboa: Editora Tavares Cardoso \& Irmão, 1899. v. I. Disponível em: https://archive.org/stream/novodiccionrio d00figugoog\#page/n85. Acesso em: 22 set. 2018.

FIGUEIREDO, C. de. Novo dicionário da língua portuguesa. Lisboa: Editora de A.M. Teixeira, 1913. v. I. Disponível em: https://archive.org/stream/dicionario-aberto. net/dict\#page/n75. Acesso em: 22 set. 2018.

FIGUEIREDO, C. L. N. de. Leitura crítica: crise do romance, crise do sujeito em Recordações do Escrivão Isaías Caminha. In: FIGUEIREDO, C. L. N. de; FERREIRA, C. M. (org.). Lima Barreto, caminhos de criação: recordações do Escrivão Isaías Caminha. São Paulo: EDUSP, 2017. p. 13-87.

FLUSSER, V. Bodenlos: uma autobiografia filosófica. São Paulo: Annablume, 2007.

HALL, S. A identidade cultural na pós-modernidade. Trad. Tomaz Tadeu da Silva; Guaracira Lopes Louro. 11.ed. Rio de Janeiro: DP\&A, 2006.

LAFETÁ, J. L. Os pressupostos básicos. In: LAFETÁ, J. L. 1930: a crítica e o Modernismo. São Paulo: Duas Cidades; Editora 34, 2000. p. 19-38.

LE TRESOR de la Langue Française informatisé. Disponível em: http://stella. atilf.fr/Dendien/scripts/tlfiv5/visusel.exe?11;s=1804909890;r=1;nat=;sol=0. Acesso em: 30 set. 2018.

LIMA BARRETO, A. H. de. Obras completas. Organizado por F. de A. Barbosa et al. São Paulo: Editora Brasiliense, 1956a. v. VI.

LIMA BARRETO, A. H. de. O Futurismo. In: LIMA BARRETO, A. H. de. Obras completas. Organizado por F. de A. Barbosa et al. São Paulo: Editora Brasiliense, 1956b. v. X. 
LIMA BARRETO, A. H. de. Contos completos de Lima Barreto. Organizado por L. M. Schwarcz. São Paulo: Companhia das Letras, 2010.

LIMA BARRETO, A. H. de. Quase ela deu o "sim"; mas.... Careta, Rio de Janeiro, p. 41-42, 29 jan. 1921. Disponível em: http://memoria.bn.br/DocReader/083712/25064. Acesso em: 22 set. 2018.

MATTELART, A.; NEVEU, É. Introdução aos estudos culturais. Trad. Marcos Marcionilo. São Paulo: Parábola Editorial, 2004.

NEEDELL, J. D. Belle époque tropical: sociedade e cultura de elite no Rio de Janeiro na virada do século. Trad. Celso Nogueira. São Paulo: Companhia das Letras, 1993.

OAKLEY, R. J. Lima Barreto e o destino da literatura. São Paulo: Editora Unesp, 2011.

RESENDE, B; VALENÇA, R. (org.). Lima Barreto: toda crônica. Rio de Janeiro: Agir, 2004. vols I - II.

PRATT, M. L. Introdução: crítica na zona de contato. In: Os olhos do império: relatos de viagem e transculturação. Trad. Jézio Hernani Bonfim Gutierre. Bauru, SP: EDUSC, 1999.

SCHWARCZ, L. M. Lima Barreto: triste visionário. São Paulo: Companhia das Letras, 2017.

SEVCENKO, N. Literatura como missão: tensões sociais e criação cultural na Primeira República. 2. ed. São Paulo: Editora Brasiliense, 1985.

TAINE, H. Introduction. In: TAINE, H. Histoire de la littérature anglaise. Paris: Hachette, 1866, v.1. E-book. Disponível em: http://www.gutenberg.org/ebooks/ 39328. Acesso em: 30 set. 2018. 